\title{
Managing thyroid disease in women planning pregnancy
}

\author{
Jennifer Yamamoto MD, Lois E. Donovan MD
}

Cite as: CMAJ 2017 July 17;189:E940. doi: 10.1503/cmaj.170021

\section{1} Women with pre-conception hypothyroidism often require increased levothyroxine once they are pregnant Increasing levothyroxine by two extra dosages per week after pregnancy is confirmed prevents development of overt hypothyroidism among most women. ${ }^{1}$ Women with a pre-conception thyroidstimulating hormone (TSH) level of $<1.2 \mathrm{mIU} / \mathrm{L}$ usually do not require an increase in levothyroxine once they are pregnant. ${ }^{2}$ Therefore, we suggest maintaining the pre-conception levothyroxine dose when the pre-conception TSH is $<1.2 \mathrm{mIU} / \mathrm{L}$, with adjustments if indicated by TSH monitoring.

2 Women should avoid ingesting levothyroxine with iron- or calcium-containing supplements

Both calcium and iron supplements have been shown to interfere with absorption of thyroid hormone. ${ }^{3}$ Ingestion of iron, calcium or prenatal vitamins should be separated from levothyroxine by at least four hours. ${ }^{3}$

\section{3}

Rates of conception and live birth are not likely influenced by minor thyroid dysfunction ${ }^{4}$

Thus, women with subclinical hypothyroidism (Box 1) or positive thyroid antibodies (thyroid peroxidase antibody, thyroglobulin antibody) who are planning pregnancy can be reassured. ${ }^{4}$ Furthermore, a randomized trial of levothyroxine therapy in women with thyroid peroxidase antibodies did not show a difference in spontaneous abortion or preterm delivery rates. ${ }^{5}$

Women with active Graves disease or toxic adenoma should delay pregnancy until normal thyroid function is established The maternal and fetal risk and benefits of available therapeutic options (antithyroid drugs, radioactive iodine, thyroidectomy) should be discussed if pregnancy is planned. Women who receive radioactive iodine should allow for clearance of radioactivity before conceiving (6 months). ${ }^{1}$

\section{Propylthiouracil is preferred for antithyroid drug treatment before conception}

Although a recent study suggests propylthiouracil may be associated with a small increase in congenital malformations, ${ }^{6}$ it is recommended for women requiring treatment for hyperthyroidism who decline radioactive iodine or thyroidectomy. ${ }^{1}$ Embryopathy secondary to methimazole use in the first trimester is well established across multiple studies. ${ }^{1}$

\section{Box 1: Definitions for thyroid disorders ${ }^{1}$}

\section{Disorder}

Overt

hypothyroidism

Subclinical

hypothyroidism

\section{Description}

TSH above the upper limit of normal with low free T4 or TSH > $10 \mathrm{mIU} / \mathrm{L}$

TSH above the upper limit of normal but $<10 \mathrm{mIU} / \mathrm{L}$, with normal free T4

Note: TSH = thyroid-stimulating hormone.

\section{References}

1. Alexander EK, Pearce EN, Brent GA, et al. 2017 Guidelines of the American Thyroid Association for the diagnosis and management of thyroid disease during pregnancy and the postpartum. Thyroid 2017;27:315-89.

2. Abalovich M, Alcaraz G, Kleiman-Rubinsztein J, et al. The relationship of preconception thyrotropin levels to requirements for increasing the levothyroxine dose during pregnancy in women with primary hypothyroidism. Thyroid 2010;20:1175-8.

3. Garber JR, Cobin RH, Gharib H, et al.; American Association of Clinical Endocrinologists and American Thyroid Association Taskforce on Hypothyroidism in Adults. Clinical practice guidelines for hypothyroidism in adults: cosponsored by the American Association of Clinical Endocrinologists and the American Thyroid Association. Thyroid 2012;22:1200-35.

4. Plowden TC, Schisterman EF, Sjaarda LA, et al. Subclinical hypothyroidism and thyroid autoimmunity are not associated with fecundity, pregnancy loss, or live birth. J Clin Endocrinol Metab 2016;101:2358-65.

5. Negro R, Schwartz A, Stagnaro-Green A. Impact of levothyroxine in miscarriage and preterm delivery rates in first trimester thyroid antibody-positive women with TSH less than $2.5 \mathrm{mIU} / \mathrm{L} . J$ Clin Endocrinol Metab 2016;101:3685-90.

6. Andersen SL, Olsen J, Wu CS, et al. Birth defects after early pregnancy use of antithyroid drugs: a Danish nationwide study. J Clin Endocrinol Metab 2013;98:4373-81.

\section{Competing interests: None declared.}

This article has been peer reviewed.

Affiliations: Department of Medicine (Yamamoto, Donovan), Division of Endocrinology and Metabolism; Department of Obstetrics and Gynecology (Donovan), University of Calgary, Calgary, Alta.

Acknowledgements: The authors would like to thank Sana Ghaznavi MD, Margaret Morris MD and Emmanuel Schaub MD for review of this manuscript.

Correspondence to: Lois Donovan, Lois.Donovan@albertahealthservices.ca 